\title{
POTENCIALIDADES TECNOLÓGICAS E EDUCACIONAIS EM AMBIENTE VIRTUAL DE ENSINO-APRENDIZAGEM LIVRE
}

\author{
Ana Claudia De Nardin - PPGE / UFSM - anaclaudiadenardin@ gmail.com \\ Fabiane Sarmento Oliveira Fruet - PPGE / UFSM - faby@ mail.ufsm.br \\ Fábio da Purificação de Bastos - MEN / PPGE / UFSM - fbastos@ ce.ufsm.br
}

\begin{abstract}
RESUMO
Por meio desse texto, apresentamos as potencialidades tecnológicas e educacionais do Ambiente Virtual de Ensino-Aprendizagem livre (Moodle - Modular Object-Oriented Dynamic Learning Environment), adotado pelo MEC como mediador-chave para Educação a Distância nas instituições federais de ensino superior e tecnológico. Por potencializar atividades educacionais construtivista e construcionista, atende aos aspectos psicológicos, pedagógicos, tecnológicos, culturais e pragmáticos destacados por Antonenko et al. (2004). Destacamos as especificidades do Moodle enfatizando seu potencial para o desenvolvimento de aprendizagem colaborativa, interação dialógico-problematizadora, interatividade, integração hipermidiática e flexibilidade cognitiva em torno dos recursos e atividades educacionais. Para tanto, a conduta docente diretiva faz-se necessária, a fim de que o potencial tecnológico e educacional do Moodle medie atividades de estudo que propiciem a participação ativa e o envolvimento de professores e estudantes.
\end{abstract}

Palavras-chave: Tecnologias da Informação e da Comunicação, Ambiente Virtual de Ensino-Aprendizagem livre, Hipermídia Educacional.

\section{TECHNOLOGICAL AND EDUCATIONAL POTENTIAL IN FREE VIRTUAL TEACHING- LEARNING ENVIRONMENT}

\begin{abstract}
We present the technological and educational potential in free Virtual Teaching-Learning Environment, Moodle (Modular Object-Oriented Dynamic Learning Environment), adopted by MEC as mediator for Distance Education in federal and technological teaching institutions. To improve constructivist and constructionist educational activities, attend the psychological, pedagogical, technological, cultural and pragmatic aspects highlighted by Antonenko et al. (2004). We emphasized the Moodle specificities highlighting its potential to develop collaborative learning, dialogical interaction, interactivity, different medias (language) integration and cognitive flexibility around resources and activities. Then, the teacher's directivity is necessary in order to the technological and educational potential of Moodle mediated study activities that allow the active participation, and the teachers and students' involvement.
\end{abstract}

Keywords: Information and Communication Technology, Free Virtual Teaching-Learning Environment, Educational Hypermedia.

\section{CONSIDERAÇÕES INICIAIS}

Devido ao avanço tecnológico, o âmbito escolar foi e ainda está sendo desafiado a inovar e promover um ensino de qualidade mediado pelos recursos tecnológicos e educacionais, o que possibilitou uma nova realidade educacional: a Educação mediada pelos Ambientes Virtuais de Ensino-Aprendizagem (AVEA). Por isso, entendemos ser fundamental que os docentes estejam preparados para interagirem com os estudantes nesse ambiente, por meio das novas ferramentas de que dispõem.

No entanto, destacamos que a inclusão do AVEA no contexto da educação não implica, necessariamente, novas práticas escolares. Assim, é essencial que os professores, ao mediarem o processo de ensino-aprendizagem por AVEA, estejam sempre procurando atualizar-se com relação a V. $7 \mathrm{~N}^{\mathrm{o}}$ 3, dezembro, 2009 
esse assunto, visando explorar ao máximo seu potencial tecnológico e educacional. Para isso, necessitamos de habilidades distintas para apresentar as informações, planejar, desenvolver e avaliar estratégias de ensino-aprendizagem, além de saber selecionar quais tecnologias são mais adequadas para determinado contexto escolar e sempre problematizá-las.

Conforme afirma Moran (2003), ensinar e aprender, hoje, não se limita ao trabalho dentro da sala de aula. Esse processo sugere uma transformação do que fazemos dentro e fora dela, no presencial e no virtual, além de um planejamento das ações de pesquisa e de comunicação que possibilitem continuar aprendendo em ambientes virtuais, acessando páginas na Internet, pesquisando textos, recebendo e enviando novas mensagens, problematizando questões em fóruns ou em salas de aula virtuais, divulgando pesquisas e projetos.

Dessa forma, os AVEA se constituem em suporte a educação a distância ${ }^{1}$ ou semipresencial ${ }^{2}$ por apresentarem características de conectividade, interface hipertextual de navegação e por integrarem em um mesmo ambiente diversas ferramentas de recursos (como materiais e conteúdos didáticos hipermidiáticos), de comunicação síncronas e assíncronas e de atividades. Isso possibilita a organização e a disponibilização de conteúdos em vários formatos, a interação, a interatividade em torno dos materiais didáticos e das ferramentas, além das atividades de colaboração e extraclasse, constituindo-se em mediadores tecnológicos das situações de ensino-aprendizagem. É tal mediação que propicia a comunicação entre docentes e discentes em torno dos materiais e atividades de determinada disciplina ou curso, permitindo a socialização das produções e a aprendizagem colaborativa.

A denominação AVEA é mais abrangente do que a terminologia Ambiente Virtual de Aprendizagem (AVA), visto que compreende e abrange as ações de ensino necessárias a aprendizagem, ou seja, enfatiza e valoriza o papel do professor em organizar, planejar, implementar e avaliar as atividades didáticas no ambiente. Desse modo, consideramos a ação diretiva docente imprescindível, pois as ações de ensinar-aprender apresentam-se como intimamente associadas.

Assim, a diferença entre um AVA e um AVEA não se resume aos aspectos operacionais ou tecnológicos e sim as potencialidades do ambiente para a comunicação e interação em um contexto em que a aprendizagem está vinculada ao ensino, e este se caracteriza pela intencionalidade pedagógica e por constituir-se em um processo sistemático, organizado e institucional/formal. Logo, é em torno de tais características do ensino que reside a diferenciação. O AVEA compreende o suporte e o acoplamento de ações de ensino-aprendizagem, constituindo o planejamento, a implementação, o registro e o acompanhamento acadêmico dos envolvidos, de acordo com a organização e intencionalidade pedagógica.

Entendemos também que os AVEA livres têm mais potencial para o processo de ensinoaprendizagem na concepção de uma educação para a prática da liberdade. Portanto, o Moodle (Modular Object Oriented-Dynamic Environment), é considerado um AVEA, porque viabiliza a associação entre as ações de ensino e aprendizagem e, por ser um software livre ${ }^{3}$, propicia a prática da liberdade. Devido a isso, o Moodle amplia a liberdade dos sujeitos, possibilitando sua execução para variados propósitos: a liberdade de aperfeiçoar, copiar, estudar e modificar o programa através do acesso ao código fonte de forma a colaborar e a beneficiar toda a comunidade. Tal aperfeiçoamento constante potencializa a apropriação do conhecimento científico-tecnológico por toda comunidade, ao permitir a prática da liberdade mediante a interação ativa de seus participantes, de forma que professores e estudantes sejam sujeitos autônomos e críticos no processo, na medida em que não se constituem apenas como usuários e consumidores das tecnologias.

Também é importante explicitar que, no Brasil, o Moodle foi homologado pelo MEC como plataforma oficial para Educação a Distância, o qual deverá ser adotado por quaisquer instituições que queiram aplicar esta modalidade de ensino. Devido a essa homologação, os cursos a distância da UAB (Universidade Aberta do Brasil) e da REGESD (Rede Gaúcha de Ensino Superior a distância) e também de outras IFES (Instituições Federais de Ensino) são mediados por esse AVEA V. $7 \mathrm{~N}^{\mathrm{o}}$ 3, dezembro, 2009 
livre.

\section{Características gerais do Moodle}

Desenvolvido por Dougiamas (2001) o Moodle foi concebido com o intuito de servir de ambiente para a aprendizagem colaborativa, uma vez que apresenta uma perspectiva construtivista. Assim, o Moodle foi desenhado para apoiar e promover a integração entre as pessoas interessadas em desenvolver ambientes de aprendizagem construtivista, centrado no aluno (Dougiamas e Taylor, 2002). Nessa perspectiva, a aprendizagem é construída através das interações sociais e no envolvimento ativo do sujeito na construção de artefatos que possam beneficiar o próprio grupo e também os outros.

O Moodle, por ser um ambiente dinâmico, orientado a objetos e modular, apresenta recursos para disponibilizar os materiais didáticos em diferentes formatos (texto, imagens, vídeos, simulações, páginas web entre outros) e também atividades (tarefas, fóruns, wikis, chat). Este aceita objetos unificados, através do padrão SCORM, por meio de um conjunto de conteúdos Web agregados em conformidade com o padrão dos objetos de aprendizagem, incluindo páginas, gráficos, programas, apresentações. Constituindo-se, dessa forma, como Modular, por servir de suporte a integração de recursos, orientado a objetos e dinâmico.

Antonenko et al. (2004) apresentam uma análise do Moodle enfatizando as particularidades do ambiente para o atendimento de cinco aspectos que caracterizam um ambiente construtivista: psicológicos, pedagógicos, tecnológicos, culturais e pragmáticos. Tais autores destacam que um ambiente construtivista que preza pelo atendimento das características cognitivas é obtido quando os estudantes estão imersos em um contexto real de aprendizagem e da relevância advinda no envolvimento com tarefas interessantes, contextualizadas e autênticas. Destacam que "a aprendizagem situada integra quatro fatores críticos que maximizam a aprendizagem dos alunos em potencial: conteúdo, contexto, comunidade e participação" (Stein apud Antonenko et al., 2004).

Os aspectos pedagógicos são referenciados pelas próprias palavras de Dougiamas (2002), que enfatiza que o docente em consonância com a metodologia construtivista deve concentrar-se sobre as experiências que sejam significativas para a aprendizagem do aluno, "em vez de apenas publicar e avaliar a informação que você acha que eles precisam saber". Isso rompe com a oposição docentediscente, uma vez que "cada participante de um curso pode ser um professor, assim como um aluno", ressignificando o trabalho docente que deixaria de assumir uma posição de "detentor de conhecimento" para assumir uma conduta de quem ensina e aprende em comunhão.

Em Vygotsky, são buscados os pressupostos da perspectiva sócio-construtivista para destacar a importância das interações sociais, do contexto e da aprendizagem enquanto uma construção social mediada pela linguagem e pela cultura. Nesse sentido, de acordo com a perspectiva construtivista, o estudante precisa estabelecer "links" entre as novas informações e os conhecimentos já existentes e ser capaz de transpor tais conhecimentos para novas situações. (Antonenko et al., 2004). Diante disso, os autores destacam o potencial construtivista do Moodle em promover "o discurso social na aprendizagem através dos módulos de comunicação síncronos e assíncronos, potencial para a formação de grupos que trabalham de forma cooperativa" e a possibilidade de compartilhar suas produções e conhecimentos (artefatos do conhecimento).

Os aspectos tecnológicos se referem a capacidade da mídia de "apoiar, limitar ou aumentar" a aprendizagem no ambiente, tais como carga cognitiva, usuabilidade e orientação. Assim, esse AVEA oferece uma estrutura de apresentação de módulos que permite controlar a apresentação do material, a identificação do caminho percorrido e a Barra de Navegação, "personalizada no topo de cada página, monitora e mostra o histórico de páginas vistas anteriormente para cada sujeito específico". A sobrecarga cognitiva, ainda segundo os autores, é reduzida no Moodle através de seções como: a) últimas notícias, que "permite o acesso instantâneo à discussão, aos lançamentos mais recentes, as 
entradas de notícias e atribuições"; e b) o calendário, o qual destaca os "eventos programados, datas e outras informações através da simples rolagem do mouse". Além disso, as possibilidades de personalização presentes no Moodle permitem aos sujeitos adicionarem aplicativos de forma a atender as necessidades individuais e coletivas.

São destacados também por Antonenko et al. (2004) os aspectos culturais que envolvem as comunidades de aprendizagens. No caso específico da comunidade Moodle, as ideias centrais são "colaboração, compartilhamento e comunidade". A construção da comunidade também está associada aos codesenvolvedores, ou seja, aqueles que visam aperfeiçoar o sistema com o intuito de disponibilizá-lo e de contribuir. Desse modo, experiências e perspectivas são integradas nas comunidades internacionais que buscam via trabalho colaborativo melhorar a qualidade do programa em seus aspectos tecnológicos e pedagógicos.

Já o atendimento ao aspecto pragmático tem como objetivo verificar como o Moodle responde às necessidades do grupo, quais são as limitações e potencialidades. Em relação a esse aspecto, os autores destacam que "o sistema é eficiente e apresenta compatibilidade entre plataformas e uma interface baseada em navegadores de tecnologia". São destacadas a disponibilidade para download, fácil administração desse ambiente advindo de uma interface gráfica simples e intuitiva e da existência de botões de ajuda, entrada de texto usando editor HTML, e ainda, as possibilidades de personalizações desse AVEA, e o suporte técnico para vários cursos oferecido gratuitamente pelos codesenvolvedores através de fóruns.

Além disso, o Moodle possui características construcionista, pois, permite diálogos e ações (diário de bordo, lição, tarefas e exercícios) e potencializa a colaboração através de ferramentas como a wiki que possibilita a composição colaborativa, a interatuação, a formação para a coparticipação ou coautoria. Constitui-se, ainda, comunicacional tendo em vista as ferramentas de comunicação assíncronas: mensagens e fóruns que criam possibilidades interacionais e potencializam o diálogo-problematizador em torno de uma temática específica; e síncronas através do chat, que propicia a problematização através da associação com materiais bibliográficos e problematização mediante a definição de questões orientadoras.

Possui também característica informacional, apresentando agendamento das atividades mediante Calendário, Notícias e Mural, e potencial Investigativo, o qual permite construir, realizar e disponibilizar pesquisas de Avaliação de forma a orientar a interação e potencializar a reflexão em torno da aprendizagem de um determinado conceito educacional. As tarefas consistem na descrição das atividades de estudo (Alberti e De Bastos, 2008) que serão desenvolvidas pelos estudantes e podem contemplar o envio em formato digital de redações, imagens, solução de problemas, projetos, possibilitando ainda o desenvolvimento de tarefas extra-classe.

Portanto, podemos afirmar que o Moodle integra princípios gerais de aprendizagem construtiva e fornece um contexto de aprendizagem online que suporta uma pedagogia centrada no estudante. Esse sistema se baseia na cognição situada e na teoria da flexibilidade cognitiva que proporcionam a oportunidade para o professor de criar um ambiente construtivista e construcionista para potencializar o ensino e a aprendizagem (Antonenko et al., 2004).

\section{Ação diretiva docente}

Na organização dos recursos e atividades em um AVEA livre, como o Moodle, acreditamos na importância da ação diretiva docente, no sentido de acompanhar e monitorar as tarefas escolares, mediadas pelas TIC. Desse modo, para que um AVEA livre medie a interação dialógicoproblematizadora e potencialize o componente investigativo, é necessário que o mesmo contenha: interface de identificação do docente e do discente de modo a preparar a interação, de acordo com as prioridades de cada um, com o intuito de que o estudante possa manusear "as ferramentas e materiais didáticos disponibilizados pelo docente e, que este possa organizar as ferramentas 


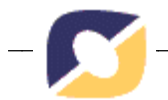

5

necessárias para o desenvolvimento das atividades de estudo; assim, como formas de avaliação e os mecanismos de interação síncronas e assíncronas” (De Bastos, Müller, 2008, p.29).

Ainda, segundo esses autores um AVEA livre precisa conter

\begin{abstract}
Mecanismos de coordenação para possibilitar agendamentos de eventos e controle do andamento das atividades escolares (quadro de avisos, programação das aulas, tarefas extraclasse, atividades de colaboração, avaliação e relatórios de participação nas atividades de estudo; mecanismos de cooperação para potencializar compartilhamentos (interação mediada pelos objetos escolares virtuais e digitais disponíveis no AVEA) e participação externa ao material didático (por exemplo, bibliotecas virtual e digital temáticas, co-autoria de educadores e educandos na reelaboração escolar) (De Bastos, et al., 2008, p.29).
\end{abstract}

Então, o Moodle possibilita a ação diretiva docente no processo de ensino- aprendizagem por ter componentes que viabilizam ao professor direcionar a programação, as atividades de estudo que são essenciais para potencializar a interação dialógico-problematizadora.

\title{
3. Interação dialógico-problematizadora e interatividade
}

O Moodle potencializa a interação dialógico-problematizadora e a interatividade na comunicação mediada por computador conectado à Internet. Cabe, portanto, além de caracterizarmos tais conceitos, evidenciando suas complementariedades e diferenças, destacarmos como são efetivados no ambiente, ou seja, como a interatividade pode potencializar a interação dialógico-problematizadora no Moodle.

Nesse sentido, a interação corresponde a uma "ação recíproca entre dois ou mais atores onde ocorre a intersubjetividade; isto é, encontro de dois sujeitos - que pode ser direta ou indireta (mediatizada por algum veículo técnico de comunicação)" (Belloni, 2008, p. 58), já a interatividade é destacada ora como potencialidade de um meio (cd, hipermídia, etc) ora como se referindo a atividade humana de ação sobre a máquina. Entendemos, então, que a interatividade se processa na ação do sujeito no computador, enquanto a interação compreende a comunicação entre os sujeitos mediados pela máquina.

De Bastos et al. (2008) defendem que "um AVEA, como o Moodle e seus objetos virtuais de ensino-aprendizagem (recursos e atividades), precisa ser abordado não apenas como um campo de aplicação de conceitos, mas como dispositivo tecnológico de comunicação e informação interativo que potencializa a interação" (p.27). Os fundamentos destacados por Silva, segundo De Bastos et al. (2008), "resguardam o sentido estrito de interação, rompendo com o processo bancário da educação ancorado na transmissão-recepção (Freire, 1987) e potencializando a liberdade neste escopo humano de cognoscência" (p.27).

Assim, a interação, no contexto do ensino-aprendizagem, pode ocorrer de dois modos: assíncrona e síncrona. A primeira não implica em uma interação simultânea. Podemos perceber que esta é o modo predominante, uma vez que o aluno, ao ler um material disponibilizado pelo professor na tela do computador ou realizar uma atividade agendada pelo docente no Moodle, e o professor, ao ler a respectiva resposta e enviar um feedback, estarão interagindo assincronamente. O correio eletrônico (mensagens), o glossário, o envio de arquivos, o fórum e o wiki são exemplos de ferramentas que possibilitam uma comunicação assíncrona. Já a segunda maneira, síncrona, é caracterizada por uma interação simultânea, a qual pode acontecer, por exemplo, por meio da ferramenta chat.

Então, compreendemos a interação dialógico-problematizadora como algo imprescindível, pois, segundo a abordagem sócio-construtivista, a apropriação dos conhecimentos se dá mediante as relações intra e interpessoais estabelecidas de forma que o diálogo-problematizador, a colaboração e a troca de experiências são significativas para a constituição do sujeito. A interação dialógico- 
problematizadora tem papel decisivo no desenvolvimento cognitivo e se efetiva, no Moodle, através das diferentes ferramentas de atividades, ao possibilitar um diálogo problematizador entre professor, tutor e aluno sobre questões problematizadoras definidas pelo docente.

\section{Integração hipermidiática das Tecnologias da Informação e da Comunicação e flexibilidade cognitiva}

O Moodle também "é fundamentado na teoria da flexibilidade cognitiva" (Antonenko et al., 2004), pois os módulos didáticos desse ambiente possibilitam aos professores apresentarem conteúdos complexos, pouco estruturados, contextualizados de modo hipermidiático, com vistas à aplicação do conhecimento adquirido para novas situações.

Assim, podemos notar que, nesse AVEA, temos a possibilidade de produzir e disponibilizar conteúdos escolares hipermídia ${ }^{4}$, nas disciplinas, por meio da integração de diferentes mídias (linguagens), o que permite o desenvolvimento da flexibilidade cognitiva.

Segundo Antonenko et al. (2004), o Moodle tem potencial para tanto, ao integrar hipermidiaticamente recursos tecnológicos e educacionais, uma vez que permite definir módulos didáticos que propiciam disponibilizar conteúdos complexos e pouco estruturados, relacionando-os a contextos reais, e também desenvolver atividades de estudo relacionadas aos conteúdos escolares que envolvam os estudantes na solução de problemas. Ou seja, o Moodle viabiliza a apresentação dos conteúdos em múltiplas perspectivas, o que contribui para o desenvolvimento de estruturas cognitivas flexíveis, possibilitando que conceitos e temas complexos não sejam tratados de forma sequencial, linear e em um só direcionamento de forma a propiciar a aplicação do conhecimento para diferentes situações.

Nesse sentido, podemos constatar que a integração hipermidiática das TIC no Moodle, a qual se constitui em hipermídia educacional (HE), viabiliza uma organização mais flexível do conhecimento escolar, além de possibilitar um acesso não linear a esse conhecimento. Dessa maneira, este pode ser estruturado de forma similar à operação da mente humana, a qual opera por associação cognitiva. Essa estruturação promove a flexibilidade cognitiva e potencializa as situações de ensinar e aprender na perspectiva dialógico-problematizadora.

Silva e Elliot (1997) também concordam que a hipermídia tem grande potencial como recurso tecnológico e educacional para a educação, capaz de apoiar o desenvolvimento de habilidades mentais e a aquisição de conhecimentos específicos. Já Machado e Santos (2004) verificaram que a hipermídia apresenta características importantes para "o desenvolvimento de atividades na área educacional, podendo tornar a aprendizagem mais motivadora e significativa, mediante os recursos audiovisuais e a capacidade de propiciar o estabelecimento de conexões entre conceitos de modo rápido e eficiente" (p.98).

De acordo com Machado e Nardi (2006), a HE viabiliza a criação de sequências de "trilhas" que podem ser percorridas em uma ordem predefinida pelo professor ou exploradas conforme o aluno tenha seu interesse despertado por determinada ideia. Dessa forma, ao percorrer o Moodle, o estudante pode estabelecer, conforme o conhecimento prévio, diversas "associações entre os assuntos inter-relacionados, mediante uma exploração ativa que favorece a ampliação de sua visão sobre um determinado tema de estudo, sua capacidade de associar ideias e a integração de novos conceitos em sua estrutura cognitiva" (Machado e Santos, 2004, p.83). Isso propicia múltiplas representações do conhecimento, para serem exploradas de acordo com percursos distintos e diferentes pontos de vista. Essa organização considera os diferentes estilos cognitivos dos alunos, ao permitir uma leitura não sequencial e não hierárquica, que ocorre conforme as necessidades do discente.

De acordo com Spiro et al. (1988 apud Carvalho, 1998), 
Para desenvolver a flexibilidade cognitiva são essenciais as abordagens de aprendizagem, ensino e representação do conhecimento que dão primazia às representações múltiplas, que vêem a aprendizagem como travessias multidireccionais e que fomentam a capacidade de reconstituir o conhecimento, oriundo de diversas fontes, para se adaptar às necessidades da nova situação, em vez de procurar um esquema précompilado que se adeque à situação. (p.169).

Além disso, acreditamos ser necessário destacar que o Moodle pode trazer benefícios para o processo educacional ao permitir que o estudante se familiarize com as TIC, visto que cada vez mais ele irá deparar-se com essas tecnologias no seu cotidiano.

\section{Aprendizagem colaborativa por meio da produção de hipermídia educacional}

Concordamos com Silva (2006), quando afirma que "homem apreende a realidade por meio de uma rede de colaboração, na qual cada ser ajuda o outro a desenvolver-se, ao mesmo tempo em que também se desenvolve. Todos aprendem juntos e em colaboração." (p.8). Segundo a autora, aprender de forma colaborativa é planejar, desenvolver ações, receber, selecionar e enviar informações, estabelecer conexões, refletir sobre o processo em desenvolvimento e em conjunto com os envolvidos, desenvolver a inter-aprendizagem; ou seja, a competência de resolver problemas em grupo e a autonomia em relação à pesquisa e ao fazer por si mesmo. Assim, podemos perceber que as informações serão selecionadas, organizadas e contextualizadas, segundo as necessidades e o conhecimento prévio momentâneos do grupo, permitindo estabelecer múltiplas e mútuas relações, atribuindo-lhes um novo sentido. O grupo que trabalha colaborativamente se torna coautor do processo de ensino-aprendizagem, visto que cada membro desse grupo será responsável pela própria aprendizagem e coresponsável pelo desenvolvimento do grupo. Por meio das interações dialógico-problematizadoras viabilizada pelas ferramentas do Moodle, cada participante do grupo confronta as próprias ideias com as do grupo, e

(...) navega entre informações para estabelecer ligações com conhecimentos já adquiridos, comunica a forma como pensa, coloca-se aberto para compreender o pensamento do outro e, sobretudo, participa de um processo de construção colaborativo, cujos produtos decorrem da representação hipertextual/hipermediática, comunicação, levantamento e teste de hipóteses e reflexões. (Silva, 2006, p.9).

Nessa perspectiva, o docente produz conhecimento junto com os estudantes e os motiva, por meio do diálogo-problematizador, a colaborarem entre si, o que favorece por um lado uma mudança de atitude em relação à participação e compromisso do professor e do aluno, uma vez que eles, nesse processo, estão procurando resolver problemas significativos para o grupo colaborativamente. O que implica em uma transformação importante e fundamental na concepção do processo de ensino-aprendizagem.

A partir disso, acreditamos ser essencial enfatizar, conforme foi constatado por Jonassen (1996), que os sujeitos, ao colaborarem uns com os outros para a produção de hipermídia, provavelmente, aprenderão mais do que apenas estudando em mídias impressas e lineares. Então, podemos observar que a ferramenta de atividade wiki do Moodle propicia a produção colaborativa e livre no âmbito da HE entre os envolvidos (professor, tutor e estudantes) no processo escolar. Isso pode acontecer devido essa ferramenta apresentar subsídios para potencializar a construção de páginas hipermidiáticas, possibilitando criar vários contextos significativos de aprendizagem e promover a observação de diferentes pontos de vista.

Portanto, de acordo com Abegg (2009), podemos afirmar que "o wiki do Moodle é uma possibilidade concreta de praticar a educação mediada pelas TIC livres, de forma colaborativa e no 
âmbito da hipermídia”. (p.58). Apresentamos, na figura abaixo, a Rede Conceitual do Moodle, visando sintetizar o potencial tecnológico e educacional desse AVEA livre.

\section{AMBIENTE VIRTUAL DE ENSINO-APRENDIZAGEM}

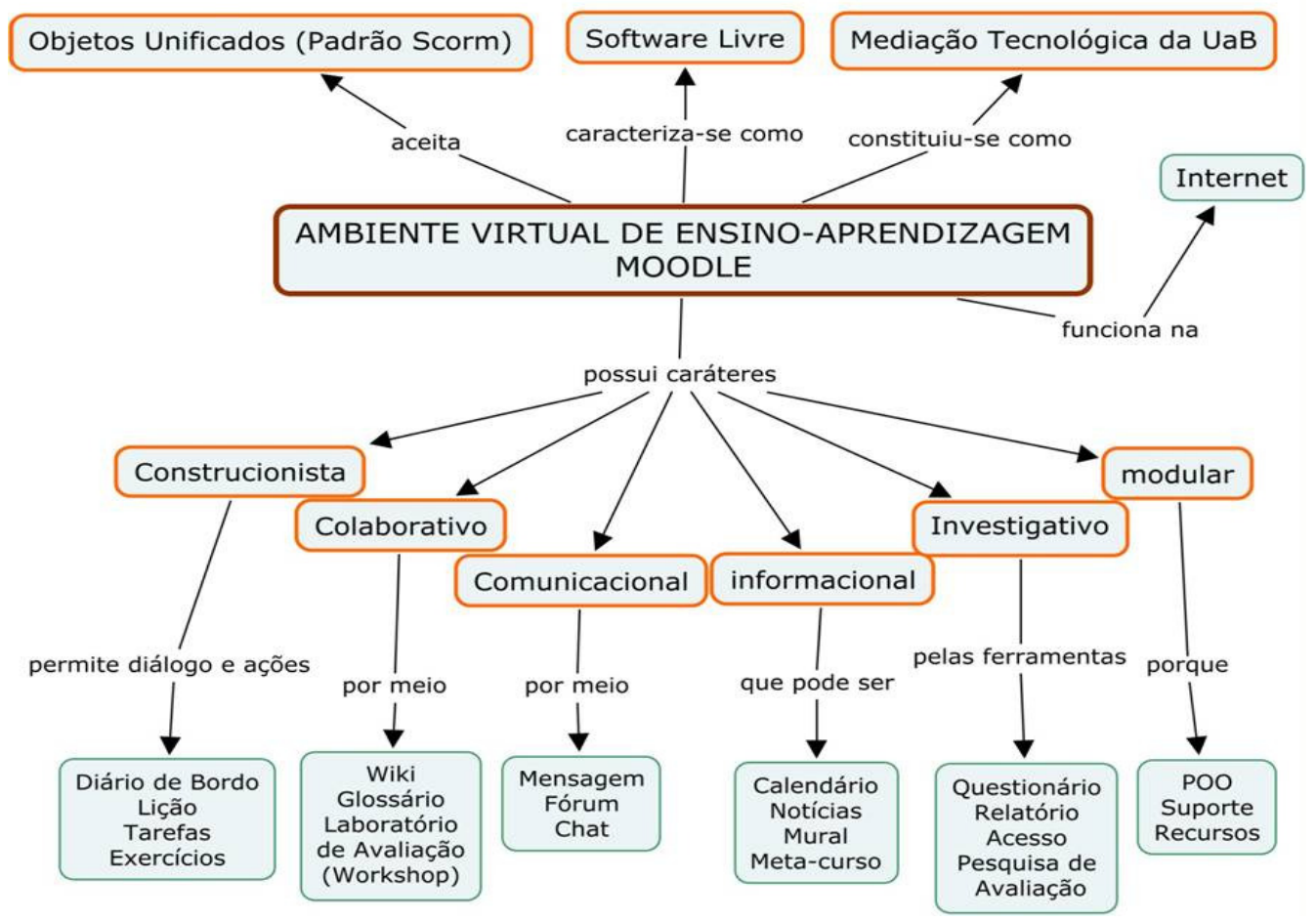

Fonte: DE BASTOS et al., 2009.

\section{CONSIDERAÇÕES FINAIS}

O ensino-aprendizagem diante dos expressivos avanços tecnológicos precisa considerar as necessidades de uma educação permanente, a produção compartilhada de conhecimentos, a autonomia, a interação e interatividade. Nesse sentido, vamos ao encontro de Belloni (2008), ao entendermos que a educação precisa problematizar o saber, contextualizar os conhecimentos, colocá-los em perspectiva, para que os alunos possam apropriar-se deles e aplicá-los em outras situações.

Para tanto, um ensino baseado na transmissão-recepção, onde os AVEA podem se converter em meros repositórios de conteúdos, necessita ser superado por uma educação dialógicoproblematizadora mediada pelas tecnologias que permitam a participação ativa do educando mediante a interação em processos dinâmicos e flexíveis. Então, a partir do que foi abordado nesse texto, podemos afirmar que o Moodle por ser uma mediação tecnológica e educacional livre, apresenta-se como propício para o processo escolar, porque esse ambiente tem grande potencial para desenvolver ações consideradas por nós fundamentais para a educação na perspectiva dialógico-problematizadora e colaborativa.

Para que isso possa ocorrer, entendemos ser de responsabilidade docente promover atividades de estudo que instiguem o envolvimento discente nas interações dialógico-problematizadoras e na V. $7 \mathrm{~N}^{\mathrm{o}}$ 3, dezembro, 2009 
aprendizagem colaborativa. Tais atividades viabilizam a coautoria e a articulação entre informações, visando adquirir novos conhecimentos e proporcionar a aplicação dos mesmos em diferentes situações; ou seja, possibilitam, aos professores e estudantes, procurarem solucionar cooperativamente as situações-problemas a partir das problematizações reais e significativas para ambos (organizadas previamente pelo docente) a fim de tornar a aprendizagem colaborativa, crítica e transformadora.

\section{REFERÊNCIAS BIBLIOGRÁFICAS}

ABEGG, I. Produção Colaborativa e Diálogo-Problematizador mediados pelas Tecnologias da Informação e Comunicação Livres. Tese de doutoramento em Informática na Educação, UFRGS, Porto Alegre, RS, 2009.

ALBERTI, T. F.; DE BASTOS, F. da P. A Teoria da Atividade como orientação psicopedagógica na implementação de atividades de estudo em Ambientes Virtuais. Ciências \& Cognição, v. 13, n.2: publicado on line em 30 de jul. 2008. Disponível em: <http://www.cienciasecognicao.org> Acesso em: 01 de dez. 2008.

ANTONENKO, P.; TOY, S.; NIEDERHAUSER, D. Modular Object-Oriented Dynamic Learning Environment: What Open Source Has To Offer. In: Association for Educational Communications and Technology, 27th, Chicago, IL, October 19-23, 2004. Disponível em: http://www.eric.ed.gov/ERICWebPortal/contentdelivery/servlet/ERICServlet?accno=ED485088

Acesso em: 25 set. 2009.

BELLONI, M. L. Educação a distância. 5º ed. Campinas, SP: Autores Associados, 2008.

CARVALHO. A.A.A. Os documentos hipermédia estruturados segundo a teoria da flexibilidade cognitiva : importância dos comentários temáticos e das travessias temáticas na transferência do conhecimento para novas situações. $\mathrm{PhD}$ thesis, Universidade do Minho, Portugal, 1998.

DE BASTOS, F.; ABEGG, I.; MALLMANN, E. M.; MÜLLER, F. M. Unidade 3 - Exemplares de Interação Mediada por Computador na Internet - atividades de estudo e colaboração utilizando a ferramenta WIKI no AVEA Moodle. In: Interação Mediada por Computador. 1. ed. EdiUFSM/UAB, Santa Maria, RS. 2008. p. 25 - 45.

DE BASTOS, F. da P (Coordenador). Regularidades e Transformações em Hipermídia Educacional. Projeto submetido ao Edital MCT/CNPq 02/2009. Ciências Humanas, Sociais e Sociais Aplicadas. Disponível em: http://itautecmoodle.proj.ufsm.br/moodle/mod/resource/view.php?id=932, Acessso em: 15 out.2009.

DOUGIAMAS, M; TAYLOR, P. C. Interpretive analysis of an internet-based course constructed using a new courseware tool called Moodle. 2002. Disponível em: <http://dougiamas.com/writing/herdsa2002/> Acesso em: 15 out. 2009. 
JONASSEN, D. O uso das Novas Tecnologias na Educação a Distância e a Aprendizagem Construtivista. Em Aberto, Brasília, v. 16, n.70, abr./jun.1996. Disponível em: $<$ http://www.rbep.inep.gov.br/index.php/emaberto/article/viewFile/1054/956> Acesso em: 05 maio 2009.

MACHADO, D. I. e SANTOS, P. L. V. A. da C. Avaliação da hipermídia no processo de ensino e aprendizagem da física: o caso da gravitação. In: Ciência \& Educação, v. 10, n. 1, 2004. p. 75-100.

MACHADO, D.I. e NARDI, R. Construção de conceitos de física moderna e sobre a natureza da ciência com o suporte da hipermídia. Revista Brasileira de Ensino de Física online, v. 28, n. 4. 2006. 1 p. 473-485. Disponível em: http://www.scielo.br/scielo.php?pid=S010247442006000400010\&script=sci_arttext\&tlng=en> Acesso em: 15 out. 2008.

MORAN, J. M. Educação inovadora presencial e a distância. 2003. Disponível em: <http://www.eca.usp.br/prof/moran/inov_1.htm> Acesso em: 05 de set. 2008.

SILVA, C. M. T. da; e ELLIOT, L. G. Avaliação da Hipermídia para Uso em Educação: uma Abordagem Alternativa. Revista Brasileira de Estudos Pedagógicos. v. 78, n. 188/189/190, Brasília. jan. / dez. 1997. p. 262-284. Disponível em: <http://rbep.inep.gov.br/index.php/RBEP/article/view/271> Acesso em: 05 maio 2009.

SILVA, A. M. P. da. Processos de ensino-aprendizagem na Era Digital. In: Anais do Congreso ONLINE del Observatorio para la CiberSociedad - Conocimiento Abierto, Sociedad Libre. 2006. $<$ http://www.cibersociedad.net/congres2006/gts/comunicacio.php?id=124\&llengua=es > Acesso em: 15 ago. 2009

STALLMAN, R. Por qué el software no debe tener propietarios. Texto online. 1994. Disponível em: <http://www.gnu.org/philosophy/why-free.es.html> Acesso em: 05 ago. 2009.

\section{NOTAS}

${ }^{1}$ Decreto $n^{\circ}$. 5.622/2005 regulamenta a Educação a distância.

${ }^{2}$ A educação semipresencial foi regulamentada pela portaria do MEC nº. 4.059/2004.

3 Os softwares livres "mantêm o espírito de que todo conhecimento deve ser compartilhado com o resto do mundo" (Stallman, 1994), a fim de aprimorá-lo e gerar novos conhecimentos.

${ }^{4}$ Entendemos por hipermídia o acoplamento computadorizado de diferentes mídias (textos, hipertextos, imagens, vídeos, animações, simulações, entre outras) com um determinado propósito, interligadas, geralmente, por links (também chamado de hiperligação). 